\title{
Seasonal and inter-annual scales of variability in phytoplankton assemblages: comparison of phytoplankton dynamics in three peri-alpine lakes over a period of 28 years
}

\author{
O. ANNEVILLE*, S. SOUISSI ${ }^{\dagger}$, S. GAMMETER ${ }^{\ddagger}$ AND D. STRAILE* \\ *Limnologisches Institut, Universität Konstanz, Konstanz, Germany \\ +Ecosystem Complexity Research Group, Station Marine de Wimereux, Université des Sciences et Technologies de Lille, \\ CNRS-UMR 8013 ELICO, Wimereux, France \\ $\ddagger$ Zurich Water Supply, Postfach, Zürich, Switzerland \\ Present address: S. Gammeter, PO Box 1279, Midland WA 6936, Australia
}

\section{SUMMARY}

1. A method based on hierarchical clustering and Bayesian probabilities is used to identify phytoplankton assemblages and analyse their pattern of occurrence and temporal coherence in three deep, peri-alpine lakes. The hierarchical properties of the method allowed ranking by order of importance of the effects of changes related to climate and to human activity on the phytoplankton structure.

2. The three deep, peri-alpine lakes (the Lower Zurich, Upper Zurich and Walen lakes) investigated in this study have been monitored since 1972. During that period they have undergone oligotrophication as a result of management programmes and they have been subject to similar meteorological effects that have led to higher water temperatures since 1988.

3. The phytoplankton assemblages of the most eutrophic lake (Lower Zurich) differ strongly from those observed in the two meso-oligotrophic lakes. Local environmental conditions appear to be the main factor responsible for species composition and change in climate characterised by the warmer water temperatures observed since 1988 have had a major impact on the winter composition of the lower basin of Lake Zurich by promoting Planktothrix rubescens.

4. Some phytoplankton assemblages are found in all the lakes. Their patterns of occurrence display strong synchrony at the annual and/or inter-annual scales. However, temporal coherence between the lakes sometimes also involves different assemblages.

5 . The reduction in phosphorus had a great influence on long-term changes in composition. In all three lakes, decreases in phosphorus are associated with a community characterised by some mixotrophic species or species adapted to low nutrient concentrations or sensitive to transparency. In the Lower Lake Zurich the decrease in phosphorus has also led to the development of species adapted to low light intensities.

6. Seasonal meteorological forcing has also induced synchronous changes, but the same assemblages are not necessarily involved, because the pool of the well-placed candidate taxa that may develop is determined by the local environmental conditions, and mainly by phosphorus concentrations. In the most eutrophic lake, the seasonal pattern is characterised by a succession of more stages. However, the seasonal assembly dynamics involve the

Correspondence: O. Anneville, INRA, Station d'hydrobiologie lacustre, 75 avenue de Corzent, BP 511, 74203 Thonon les Bains Cedex, France. E-mail: orlane.anneville@thonon.inra.fr 
succession of species sharing common selective advantages that make them relatively stronger under these nutrient and light conditions.

Keywords: Lake Walen, Lake Zurich, multivariate analyses, phosphorus, temporal coherence

\section{Introduction}

In the 20th century, human activities which introduced excess nutrients into lakes caused significant changes in phytoplankton communities (e.g. the occurrence of phytoplankton blooms and the appearance of harmful species) that often interfere with human use of water (Paerl, 1988). During the past 30 years, loading from sewage and industry has been reduced significantly in Europe, North America and other industrial countries (Sas, 1989). As a consequence, phosphorus concentrations have fallen substantially in many lakes. These falling nutrient concentrations occur in a context of seasonal and long-term meteorological changes (Anneville et al., 2002a). Meteorology also plays a major role in the dynamics of aquatic systems. Phytoplankton communities experience climate change indirectly through changes in lake level, ice-out time, stratification, nutrient inputs and zooplankton grazing (Straile et al., 2003). These environmental changes affect species in many different ways, altering their productivity, their interactions with other species, behaviour and composition (Harrington, Woiwod \& Sparks, 1999; Straile et al., 2003). Understanding the combined effects of environmental drivers on species, communities and ecosystems is a key challenge for research management (Breitburg et al., 1999; Folt et al., 1999; Harrington et al., 1999). Another challenge for research management concerns the understanding of temporal coherence (Magnuson, Benson \& Kratz, 1990). Temporal coherence is defined as the degree to which different lakes behave similarly or dissimilarly through time' (Magnuson \& Kratz, 2000). It is an important property to evaluate in order to be able to extrapolate the results from a lake or set of lakes and for using adjacent lakes as references to evaluate treatment effects in manipulative whole lake experiments. Furthermore, comparative analyses of longterm phytoplankton dynamics can help to obtain a more general understanding of changes with respect to external and internal drivers of these dynamics (Koenig, 1999; Magnuson \& Kratz, 2000).
To understand the response of a system to changes in multiple drivers and to make intersite comparisons requires comparable sets of long-term data. Monitoring of Lake Walen and the two basins of Lake Zurich started in the 1970s and provides a valuable resource to tackle these questions. In this study we explore both seasonal and interannual patterns of phytoplankton assemblages and successions, all of which are subject to combined environmental changes. The main objectives of this paper are to distinguish between and rank the factors related to climate and human activity that generate the phytoplankton structure and, finally, to discuss their influence on the temporal coherence in different lakes.

Different results may be obtained depending on the point of view, for ecosystems are fundamentally structured in space and time (Frontier \& Pichod-Viale, 1991). The problem is not to choose the correct scale of description, because the scale of observation (spatial, monthly, annual) is generally chosen deliberately to elucidate key features of the systems (Levin, 1992). What matters is recognising that changes are taking place on several scales at the same time. As a consequence, cross-scale studies then appear to be critical for the identification and hierarchical ordering of the factors generating variability (Levin, 1992). Relating community structural dynamics across scales requires a multivariate method that treats several dimensions simultaneously and thus can take into account both the variability between the different locations (spatial scale) and the variability between successive samples (temporal scale). Numerical analysis procedures have been developed to interpret large space/time datasets (Beaugrand, Ibanez \& Reid, 2000), such as the three-mode PCA, which can decompose total variance into spatial and temporal variances. In this study we use a more recent method that combines hierarchical clustering, Bayesian probability and the determination of species associations (Souissi et al., 2001). This method has been revised and applied to the Lake Geneva phytoplankton time-series (Anneville et al., 2002a). It defines phytoplankton structures by keeping the information obtained at the 
sampling frequency time scale, and maps the seasonal and interannual changes of phytoplankton assemblages (at several hierarchy levels) using Bayesian probabilities. Analysing these graphics makes it possible to consider different levels of within-cluster variability, and this makes it possible to classify structures in order of importance. Finally, the method used has the advantage of associating each cluster with a phytoplankton assemblage and then measuring the probabilities that the samples contain the phytoplankton assemblages. On the basis of these probabilities, it is possible to analyse the temporal synchronism between the lakes for the different levels of hierarchy.

\section{Methods}

\section{Study sites characteristics}

The peri-alpine lakes studied are monomictic and located in Switzerland (Fig. 1). Lake Zurich is separated into two basins by a natural dam. We thus distinguish between the lower basin (LZ) and the upper basin (UZ), both of which are situated downstream from Lake Walen. Consequently, the three lakes are hydrologically linked. Water flows from Lake Walen into UZ and from there into LZ. UZ receives approximately $65 \%$ of its annual inflow from Lake Walen whereas LZ receives $95 \%$ of its annual inflow from UZ. All three lakes are relatively deep with maximum depths of $145 \mathrm{~m}$ (Lake Walen), $136 \mathrm{~m}$ (LZ) and $48 \mathrm{~m}$ (UZ).
Being located near to each other and at approximately the same altitude (Walen: $419 \mathrm{~m}$, Zurich: $406 \mathrm{~m}$ ), the lakes are influenced by similar meteorological forcing. During the period studied we distinguished a cold period (1976-87) from a warmer period (1988-2000) in all lakes (Fig. 2a). The warm period, observed since 1988, is characterised by a positive phase of the North Atlantic Oscillation (NAO). It is a meteorological phenomenon that significantly influences the air temperature in Europe (Hurrell, 1995) and synchronises the fluctuations in water temperatures and plankton succession (Straile, 2002; Straile et al., 2003). However, important local climatic factors also influence the lakes substantially. Lake Walen is fully exposed to westerly winds, as it lies between steep mountains. In contrast, $\mathrm{UZ}$ and $\mathrm{LZ}$ are protected from westerly winds by hills extending further northsouth direction. These differing exposures to winds lead to quite different impacts on stratification stability and on the depth of the epilimnion. Additionally, Lake Walen is destratified as a result of receiving most of its water from one alpine river, which has high amplitude in annual discharge reaching its maximum in early summer.

The three lakes underwent eutrophication and then, since the early 1970s, total phosphorus concentrations have been decreasing (Fig. 2b). In Lake Walen, the peak of phosphorus concentration was about $30 \mu \mathrm{gP} \mathrm{L}^{-1}$ during the 1970s, which is the same as $\mathrm{LZ}$ is experiencing now. In recent years, concentrations in Lake Walen have fallen to below $5 \mu \mathrm{gP} \mathrm{L} \mathrm{L}^{-1}$

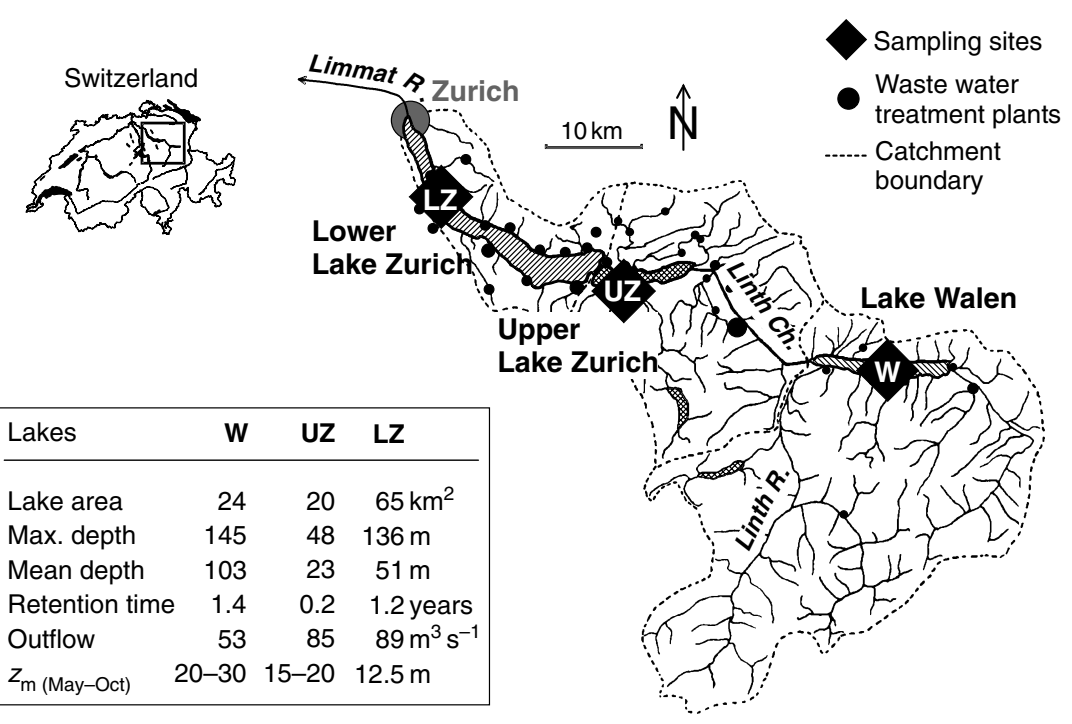

Fig. 1 Geographical situation of Lake Walen and Upper and Lower Lake Zurich with a map showing the hydrological catchment and indicating the locations of the three sampling stations. 
(a)

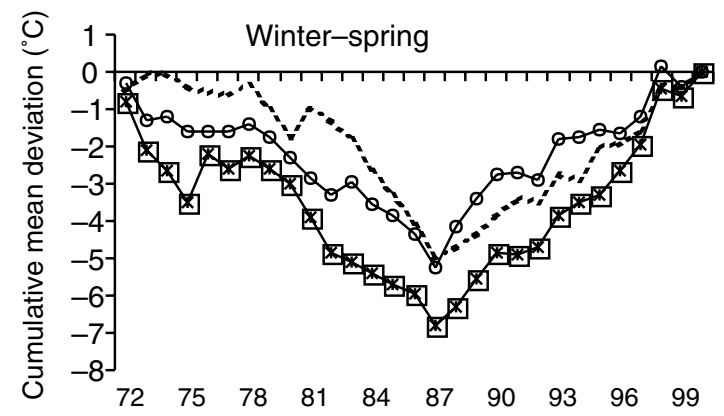

(b)

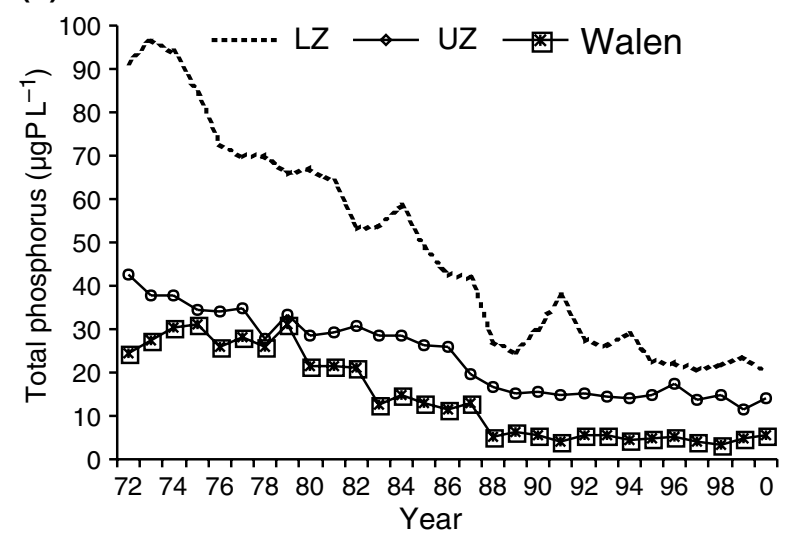

Fig. 2 (a) Cumulative deviation of the water temperatures in Lower Lake Zurich (LZ), Upper Lake Zurich (UZ) and Lake Walen from the average of water temperature measured during winter and spring from 1972 to 2000. Increasing slopes indicate successions of warmer years. (b) Long-term changes in winter total phosphorus concentrations in Lower Lake Zurich (LZ),

Upper Lake Zurich (UZ) and Lake Walen from 1972 to 2000.

(usually below the detection limit), whereas they are over $10 \mu \mathrm{gP} \mathrm{L}{ }^{-1}$ and $20 \mu \mathrm{gP} \mathrm{L}{ }^{-1}$ respectively in UZ and LZ.

\section{Sampling strategy}

The data used in this study were obtained by monitoring the pelagic zones. Phytoplankton sampling and species determination were performed by the same methods throughout the investigation period. Sampling for phytoplankton determination has been performed once a month since 1972 and covers the first $20 \mathrm{~m}$. Phytoplankton identifications and cell counts were carried out in sedimentation chambers under an inverted microscope (Utermöhl, 1958). The small centric diatoms could not be clearly identified under the microscope and Cyclotella were probably often misclassified as Stephanodiscus. To allow for this, when not clearly identified, we combined these taxa into one category: Cyclotella/Steph. In order to homogenise the database and to reduce potential errors in species identification, only genera were taken into consideration in this analysis.

\section{Statistical analyses}

The matrix used in this study includes all the samples from the three lakes (a total of 1049 samples). In order to outline the pattern of species occurrences and minimise the noise generated by rare species, only the more frequent species have been included in the analysis; 46 phytoplankton genera, which were present in more than $32 \%$ of the total number of samples, were selected (Table 1).

The statistical method makes it possible to characterise phytoplankton assemblages and, by computing the probabilities that given assemblages will occur, it provides a new way of analysing temporal successions of these assemblages at both the annual and seasonal scales. The method was described in detail by Souissi et al., 2001 and Anneville et al., 2002a, but we give a brief summary here (Fig. 3).

(a) A principal component analysis (PCA) was applied to the log-transformed data in order to obtain the multinormality required for the computation of the Bayesian probabilities.

(b) Hierarchical clustering, with Euclidean distances and flexible linkage was performed on the first 34 axes of the PCA scores, which account for more than $94 \%$ of the total variance and fulfil the required multinormality condition for Bayesian probability computation (Souissi et al., 2001). This was carried out to obtain effective separation into clusters for the subsequent cartography.

(c) The level of heterogeneity between each sample and the properties of each cluster were obtained by calculating the conditional Bayesian probability. In other words, the dendrogram output can be used to calculate the probability that a given sample belongs to a specific cluster. This analysis was performed for several successive hierarchical levels of the dendrogram.

(d) The advantage in using dendrograms is that different 'resolutions' can be obtained from the dataset depending on the choice of cut-off level; i.e. the first cut-off level produces two clusters, the next 
Table 1 List of the phytoplankton taxa used in the analysis. The following characteristics are specified in the table: Abbrev, abbreviated name used in the paper; GrTax, the taxonomic group (Cya, cyanophyte; Din, dinoflagellate; Cry, cryptophyte; Chr, chrysophyte; Dia, diatom; Chl, chlorophyte; Con, conjugate); Trophy (H, hypertrophic; E, eutrophic; M, mesotrophic; O, oligotrophic); Strategy (strategy according to Reynolds, 1997: C, competitor; S, stress-tolerant; R, disturbance-tolerant ruderal); Size; (Micro, microplankton; Nano, nanoplankton), information about the mobility and the mixotrophy, the percentage of occurrence (Occ), the average biomass ( $\mu \mathrm{g} \mathrm{L}{ }^{-1}$, fresh weight) in all lakes and for each lake. Main data sources for the ecological characteristics regarding the trophy and strategy are from personal communications, Seip \& Reynolds, 1995; Reynolds, 1996; Reynolds, 1997; Lindenschmidt \& Chorus, 1998; Elliott et al., 2000; Reynolds et al., 2002

\begin{tabular}{|c|c|c|c|c|c|c|c|c|c|c|c|c|}
\hline \multirow[b]{2}{*}{ Genera } & \multirow[b]{2}{*}{ Abbrev. } & \multirow[b]{2}{*}{ GrTax } & \multirow[b]{2}{*}{ Trophy } & \multirow[b]{2}{*}{ Strategy } & \multirow[b]{2}{*}{ Size } & \multirow[b]{2}{*}{ Motility } & \multirow[b]{2}{*}{ Mixotrophy } & \multirow{2}{*}{$\begin{array}{l}\text { Occ } \\
(\%)\end{array}$} & \multirow{2}{*}{$\begin{array}{l}\text { Average } \\
\text { biomass }\end{array}$} & \multicolumn{3}{|c|}{ Average biomass } \\
\hline & & & & & & & & & & Walen & $\mathrm{UZ}$ & $\mathrm{LZ}$ \\
\hline Amphora & Amph & DIA & & & Micro & $\mathrm{N}$ & & 42 & 0.1 & 0.1 & 0.2 & 0.1 \\
\hline Ankyra & Ank & $\mathrm{CHL}$ & $\mathrm{E}$ & $\mathrm{C}$ & Micro/Nano & $\mathrm{Y}$ & & 58 & 1.8 & 0.9 & 1.7 & 2.6 \\
\hline Aphanizomenon & Aphan & CYA & $\mathrm{E}$ & CS & Micro & $\mathrm{Y}$ & & 65 & 20.9 & 0.1 & 11.0 & 51.5 \\
\hline Asterionella & Aster & DIA & $\mathrm{M} / \mathrm{E}$ & $\mathrm{R}$ & Micro & $\mathrm{N}$ & & 99 & 71.9 & 59.9 & 108.7 & 47.2 \\
\hline Ceratium & Cer & DIN & $\mathrm{M} / \mathrm{E}$ & CS- S & Micro & $\mathrm{Y}$ & $\mathrm{Y}$ & 76 & 51.0 & 69.9 & 28.4 & 54.5 \\
\hline Chlamydomonas & Chla & $\mathrm{CHL}$ & & $\mathrm{C}$ & Nano & $\mathrm{Y}$ & & 33 & 4.0 & 0.3 & 8.9 & 2.8 \\
\hline Closterium & Clos & $\mathrm{CON}$ & & & Micro & $\mathrm{N}$ & & 64 & 3.4 & 0.1 & 2.3 & 7.8 \\
\hline Cocconeis & Cocc & DIA & & & Micro & $\mathrm{N}$ & & 40 & 0.1 & 0.1 & 0.2 & 0.1 \\
\hline Coеnococcus & Coe & $\mathrm{CHL}$ & $\mathrm{M}$ & & Micro & $\mathrm{N}$ & & 43 & 6.5 & 1.7 & 2.2 & 15.5 \\
\hline Cosmarium & $\operatorname{Cos}$ & $\mathrm{CON}$ & $\mathrm{M}$ & $\mathrm{R}$ & Micro & $\mathrm{N}$ & & 77 & 0.5 & 0.5 & 0.3 & 0.6 \\
\hline Cryptomonas & Cry & CRY & $\mathrm{M} / \mathrm{E}$ & CS-CRS & Micro & $\mathrm{Y}$ & $\mathrm{Y}$ & 100 & 106.4 & 58.0 & 114.0 & 147.3 \\
\hline Cyclotella & Cyc & DIA & $\mathrm{O} / \mathrm{M}$ & $\mathrm{CR}$ & Nano & $\mathrm{N}$ & & 33 & 5.6 & 5.5 & 6.9 & 4.4 \\
\hline Cyclotella/Steph & Cyc/Steph & DIA & $\mathrm{O} / \mathrm{M}$ & $\mathrm{CR}$ & Nano & $\mathrm{N}$ & & 99 & 63.8 & 67.3 & 69.4 & 54.6 \\
\hline Cymbella & Cym & DIA & & C-R & Micro/Nano & $\mathrm{N}$ & & 76 & 0.5 & 0.5 & 0.6 & 0.4 \\
\hline Diatoma & Diat & DIA & $\mathrm{H}$ & $\mathrm{R}$ & Micro & $\mathrm{N}$ & & 83 & 14.0 & 20.7 & 11.7 & 9.6 \\
\hline Dinobryon & Dino & CHR & $\mathrm{O} / \mathrm{M}$ & R-CS & Micro & $\mathrm{Y}$ & $\mathrm{Y}$ & 80 & 60.2 & 69.3 & 72.2 & 39.1 \\
\hline Elakatothrix & Elak & $\mathrm{CHL}$ & $\mathrm{O} / \mathrm{M}$ & & Micro & $\mathrm{N}$ & & 71 & 0.5 & 0.3 & 0.3 & 1.0 \\
\hline Erkenia & Erk & CHR & $\mathrm{O} / \mathrm{M}$ & & Nano & $\mathrm{Y}$ & $\mathrm{Y}$ & 81 & 27.7 & 22.2 & 22.7 & 38.1 \\
\hline Fragilaria & Frag & DIA & $\mathrm{E}$ & $\mathrm{R}$ & Micro/Nano & $\mathrm{N}$ & & 99 & 210.7 & 287.9 & 140.9 & 203.3 \\
\hline Gomphonema & Gomp & DIA & & & Micro & $\mathrm{N}$ & & 65 & 0.5 & 0.7 & 0.7 & 0.2 \\
\hline Gymnodinium & Gymno & DIN & & $\mathrm{S}$ & Nano/Micro & $\mathrm{Y}$ & $\mathrm{Y}$ & 99 & 21.9 & 13.3 & 17.5 & 35.0 \\
\hline $\begin{array}{l}\text { Heterotrophic } \\
\text { nanoflagellates }\end{array}$ & Hnf & & & & Nano & $\mathrm{Y}$ & & 100 & 74.8 & 61.0 & 79.9 & 83.4 \\
\hline Kephyrion & Keph & CHR & & & Nano & $\mathrm{Y}$ & $\mathrm{Y}$ & 61 & 5.3 & 2.7 & 10.6 & 2.5 \\
\hline Kirchneriella & Kirch & $\mathrm{CHL}$ & & & Nano & $\mathrm{N}$ & & 44 & 3.1 & 4.5 & 2.7 & 2.2 \\
\hline Lyngbya & Lyn & CYA & & & Micro & $\mathrm{N}$ & & 35 & 0.1 & 0.0 & 0.0 & 0.3 \\
\hline Mallomonas & Mal & CHR & $\mathrm{O} / \mathrm{M}$ & & Micro/Nano & $\mathrm{Y}$ & $\mathrm{Y}$ & 52 & 8.1 & 4.1 & 15.8 & 4.3 \\
\hline Melosira & Melo & DIA & & & Micro & $\mathrm{N}$ & & 73 & 111.8 & 71.1 & 151.9 & 112.5 \\
\hline Microcystis & Micr & CYA & $\mathrm{E}$ & $S$ & Micro & $\mathrm{N}$ & & 43 & 2.8 & 0.4 & 1.3 & 6.7 \\
\hline Monas & Mon & CHR & & & Nano & $\mathrm{Y}$ & & 76 & 24.3 & 20.8 & 23.8 & 28.2 \\
\hline Mougeotia & Moug & $\mathrm{CON}$ & & & Micro & $\mathrm{N}$ & & 48 & 10.0 & 1.3 & 5.9 & 22.6 \\
\hline Navicula & Nav & DIA & & & Micro/Nano & $\mathrm{N}$ & & 94 & 2.1 & 2.1 & 2.4 & 1.9 \\
\hline Nitzschia & Nitz & DIA & & $\mathrm{R}$ & Micro & $\mathrm{N}$ & & 90 & 5.3 & 11.5 & 2.6 & 1.8 \\
\hline Oocystis & Ooc & $\mathrm{CHL}$ & $\mathrm{M}$ & $\mathrm{S}-\mathrm{C}$ & Nano/Micro & $\mathrm{N}$ & & 56 & 10.2 & 0.7 & 2.3 & 27.7 \\
\hline Pandorina & Pand & $\mathrm{CHL}$ & & & Micro & $\mathrm{Y}$ & & 68 & 31.3 & 13.3 & 23.9 & 56.7 \\
\hline Pediastrum & Pedia & CHL & $\mathrm{E}$ & CR & Micro & $\mathrm{N}$ & & 35 & 1.1 & 0.2 & 0.6 & 2.3 \\
\hline Peridinium & Perid & DIN & $\mathrm{M} / \mathrm{E}$ & $S$ & Micro & $\mathrm{Y}$ & $\mathrm{Y}$ & 72 & 25.7 & 22.7 & 20.0 & 34.3 \\
\hline Phacotus & Phac & $\mathrm{CHL}$ & & & Nano & $\mathrm{Y}$ & & 58 & 1.3 & 0.0 & 0.6 & 3.2 \\
\hline Picoplankton & Pico & CHL & & & Nano & $\mathrm{N}$ & & 100 & 6.4 & 5.3 & 7.2 & 6.8 \\
\hline Planktothrix & Plan & CYA & $\mathrm{M} / \mathrm{E}$ & R-RS & Micro & $\mathrm{Y}$ & & 61 & 162.8 & 1.4 & 9.1 & 477.3 \\
\hline Pseudopedinella & Pseud & $\mathrm{CHR}$ & & & Nano & $\mathrm{Y}$ & & 37 & 0.4 & 0.4 & 0.5 & 0.3 \\
\hline Rhodomonas & Rhod & CRY & $\mathrm{M} / \mathrm{E}$ & $\mathrm{C}$ & Nano & $\mathrm{Y}$ & $\mathrm{Y}$ & 100 & 92.2 & 79.3 & 92.3 & 105.0 \\
\hline Scenedesmus & Scen & $\mathrm{CHL}$ & $\mathrm{E} / \mathrm{H}$ & $\mathrm{CR}$ & Nano & $\mathrm{N}$ & & 38 & 0.3 & 0.0 & 0.3 & 0.7 \\
\hline Staurastrum & Staur & $\mathrm{CON}$ & $\mathrm{M} / \mathrm{E}$ & & Micro & $\mathrm{N}$ & & 60 & 4.3 & 1.4 & 1.9 & 9.4 \\
\hline Stephanodiscus & Steph & DIA & $\mathrm{E} / \mathrm{H}$ & $\mathrm{C}$ & Micro & $\mathrm{N}$ & & 90 & 21.6 & 18.7 & 22.5 & 23.6 \\
\hline Synedra & Syn & DIA & $\mathrm{M} / \mathrm{H}$ & CR & Micro & $\mathrm{N}$ & & 92 & 15.0 & 10.1 & 10.6 & 24.4 \\
\hline Tabellaria & Tab & DIA & $\mathrm{M}$ & $\mathrm{R}$ & Micro & $\mathrm{N}$ & & 78 & 58.3 & 90.4 & 37.6 & 46.9 \\
\hline
\end{tabular}




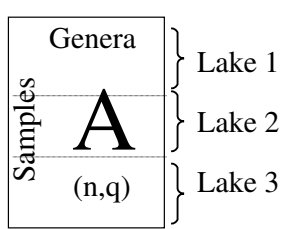

(a) PCA and test of multinormality

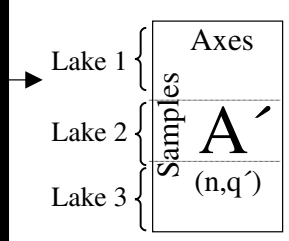

(b)

Hierarchical classification of samples

(e) Indicator values (IndVal) for each cluster and each cut off level

\section{- Similarity between samples +}

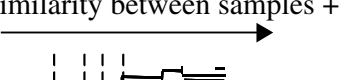

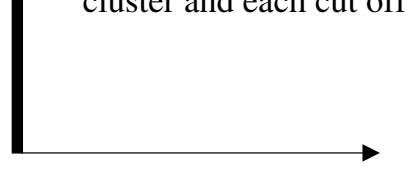

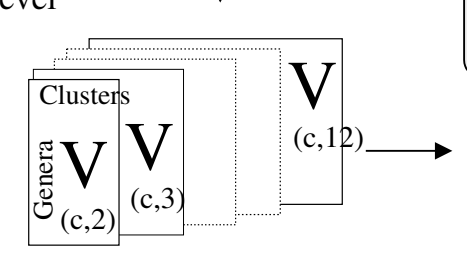

Hierarchisation of the patterns of variability

probabilities for Lake 3\{

each cut-off level

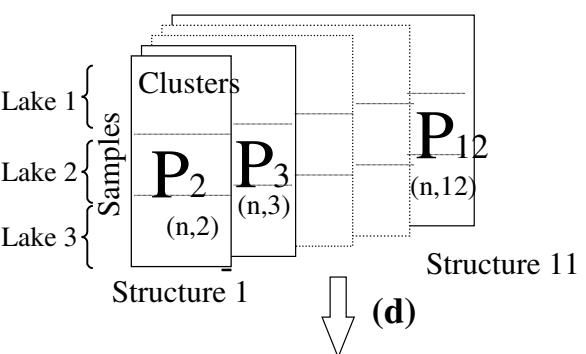

Selection of genera with IndVal $>25$

so that each cluster $=1$ phytoplankton assemblage

Temporal maps of phytoplankton assemblage isoprobabilities

Fig. 3 Flowchart of the main steps in the numerical analysis applied to the phytoplankton genera of Lakes Walen and Zurich: (a) computation of a PCA of the log-transformed data, (b) hierarchical classification of the samples, (c) computation of the conditional probabilities for each level of resolution, (d) mapping the isoprobabilities of the clusters, (e) characterisation of phytoplankton assemblages and substitution of the phytoplankton assemblages to the clusters.

level produces three clusters etc. In this case a limit was placed on the eleventh cut off level, resulting in $11+1$ clusters. The successive structure defined by the dendrogram results from classification of sufficiently similar samples, according to the phytoplankton genera, into the same cluster and from the degree of difference between the clusters. Assigning a sample to a cluster requires that the similarity of the samples with the other samples of the cluster is at least equal to the level of partition under consideration. As a consequence, each cut-off-level of the dendrogram corresponds to a level of precision that can be associated to 'within-cluster heterogeneity'. As the level of partition increases, the precision increases and the 'within-cluster heterogeneity' decreases. Considering each level of partition thus progresses along a scale of precision, and forces generating the observed structures being placed in hierarchical order.

For each cluster of samples obtained at each resolution (cut-off level), a map of isoprobabilities is created for each lake. These maps describe the seasonal (on the abscissa) and interannual (on the ordinates) patterns of the probabilities of occurrence. The values of probabilities are represented by five classes from 0 to 1 with an interval of 0.2 .

(e) After mapping the temporal patterns of the clusters the genera that best characterise each cluster were identified by using the indicator value index (IndVal) proposed by Dufrêne \& Legendre (1997), as in the case of Souissi et al. (2001) and Anneville et al. (2002a). This index measures the specificity (measure of affiliation) and fidelity (measure of occurrence) of a genus for a group. The genera which best characterise a cluster are those which present high an IndVal. The set of genera with the highest IndVal make up a phytoplankton assemblage. To characterise an assemblage we retained the genera with an IndVal above the arbitrary threshold of $25 \%$. If a cluster has no indicator taxa with IndVal $>25 \%$, this means that the phytoplankton communities in the samples making up this 
cluster were not sufficiently similar or specific to identify taxa with high fidelity and specificity indices.

Then, at this stage, a phytoplankton assemblage characterises each cluster. The maps of isoprobabilities created for each cluster can be interpreted as a temporal map for the pattern of the corresponding phytoplankton assemblage.

Trends in water temperature and probabilities of occurrence were analysed and compared using the cumulative function. This function gives the dates, intensity and duration of any change (Ibanez, Fromentin \& Castel, 1993). It is obtained, for each variable, by subtracting a reference value (mean of the series, indicative value) from the respective data, and then successively adding the residuals. Increasing and decreasing slopes thus indicate successive values, which were respectively higher and lower than the reference value.

\section{Results}

\section{Recognition of phytoplankton assemblages}

The organisation of samples within clusters was analysed using the first 11 cut-off levels of the dendrogram. Each cluster of samples was associated with a phytoplankton assemblage. Fig. 4 summarises the composition of successive assemblages, which are associated with the two newly formed clusters after splitting the parental cluster. Most of the genera used in this study have the greatest power of characterisation (i.e. have the highest IndVal) for the assemblages A1_1 and A1_2 of the first structure, and assemblages A2_2 and A3_2 that appear respectively at the second and third level of resolution. The number of indicator genera (with IndVal $>25 \%$ ) decreases with the level of resolution, and few genera are represented at the highest level of resolution. This

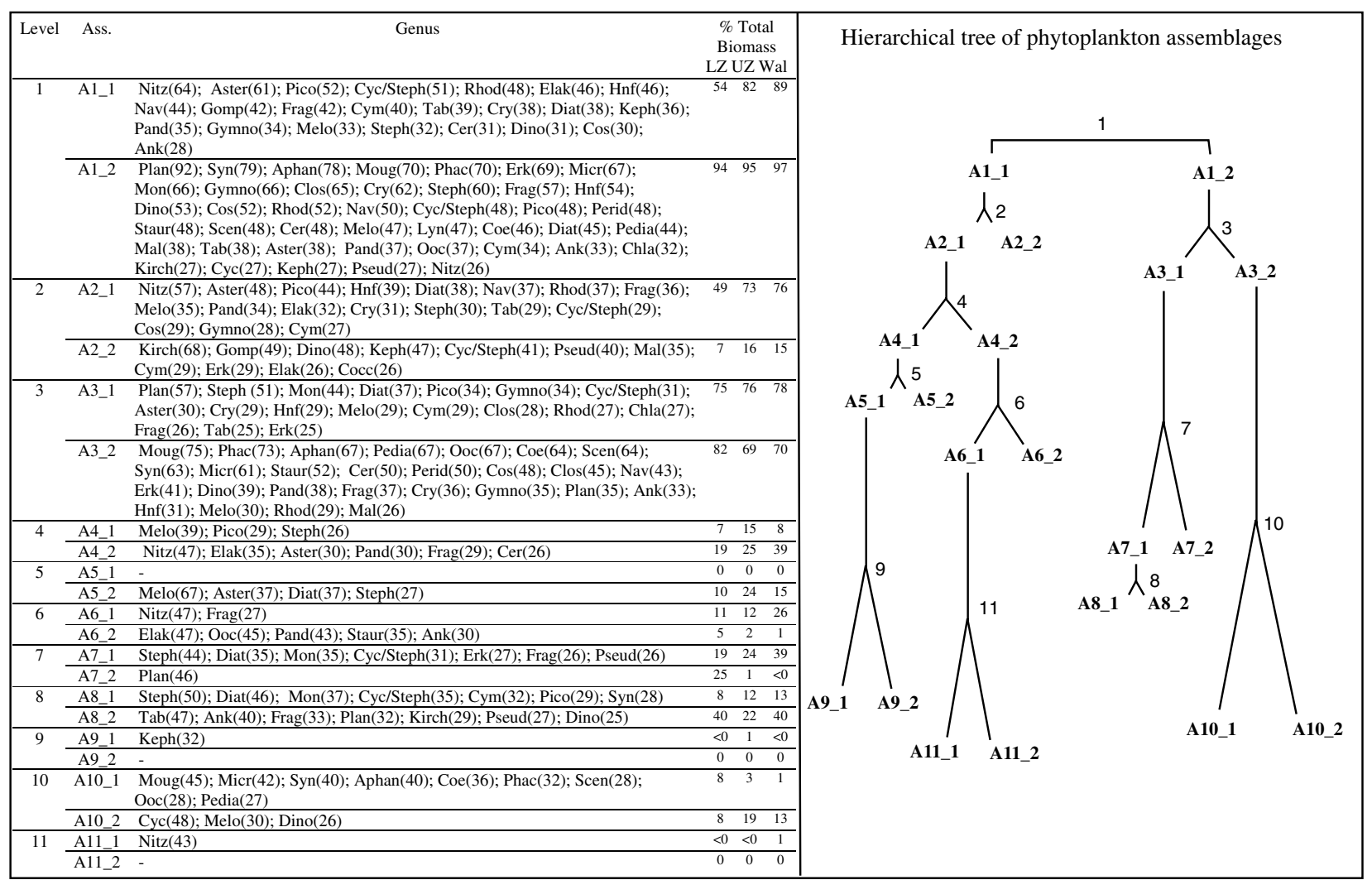

Fig. 4 Hierarchical tree of phytoplankton assemblages and composition of the successive assemblages identified at the various levels of resolution. The IndVal value is specified for each genus. Contributions of assemblage to the total phytoplankton biomass are indicated for each lake separately. The level of resolution represents differences: 1, between LZ and UZ-Walen; 2, before and after 1990; 3, between summer and winter-spring in LZ; 4, between summer and winter-spring; 5, between the winters of 1970 to mid1980s and the other winters; 6, between 1970s to 1980s early summer in LZ and summer-late summer in UZ and Walen; 7, between winter and spring in LZ; 8, between spring and 1990s summers in LZ; 9, before and after 1980; 10, between early summer in LZ and late summer in LZ and UZ; 11, summers before and after 1988 in UZ and Walen. 
means that in these lakes, the phytoplankton occurrence is fuzzy at the higher levels of resolution. Consequently, the precision of an analysis can only be improved up to a threshold beyond which the occurrence of the taxa becomes too random for identifying characteristic assemblages.

\section{Classification of phytoplankton by their level} of appearance

The hierarchical clustering method makes it possible to classify structures in the phytoplankton community. Comparisons of the two new assemblages that appear at successive levels of resolution are expected to provide information about the nature of the stressor responsible for this distinction. The importance for community organisation, of such a stressor that distinguishes between two new assemblages is assumed to decrease when the level of precision increases. Successive comparisons between the two new assemblages should therefore provide answers to the question about the coupling and intensity of stressors on phytoplankton dynamics. The analyses of the patterns of occurrence of the different assemblages obtained at different hierarchical levels will be described below.

\section{Description of the pattern of occurrence of the} assemblages appearing at successive cut-off levels

The temporal maps of isoprobabilities provide information about the patterns of occurrence for each assemblage. For each hierarchical level, the occurrence of a phytoplankton assemblage is described via a probability value ranging from 0 to 1 (Figs 5 and 7). Based on these probabilities, distinct patterns in phytoplankton assemblages appear:

Structure 1: interlake and long-term variability. The first level of resolution underlines the floristic differences between Lake LZ and the other two lakes (Fig. 5). At this step there is a separation between an assemblage A1_1, characterised by genera such as Nitzschia, Asterionella, Cyclotella, and A1_2, which is characterised by a lot of taxa, and particularly by Planktothrix, Synedra, Aphanizomenon, Erkenia (Fig. 4). For A1_1 the probability of occurrence is greater than 0.5 throughout almost the whole series in Lake Walen and UZ
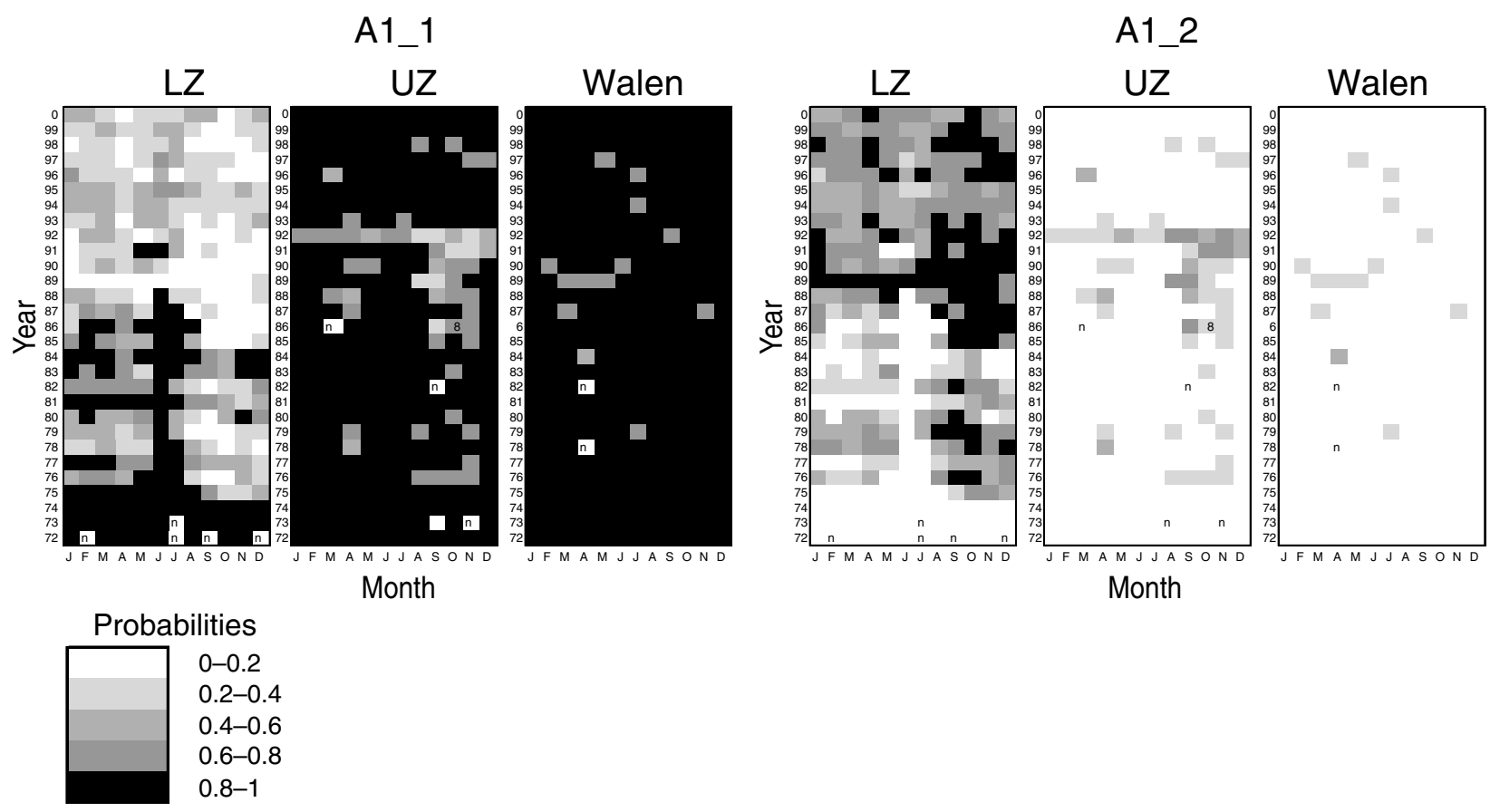

Fig. 5 Temporal maps of isoprobabilities describing the patterns of occurrence for the two assemblages, A1_1 and A1_2. In each map, the time scale (years, from 1972 to 2000) runs from bottom to top and the season scale (months, from January to December) runs from left to right. The letter ' $n$ ' indicates the months with no sampling and the darker the pixels, the higher the probabilities. 
(a)

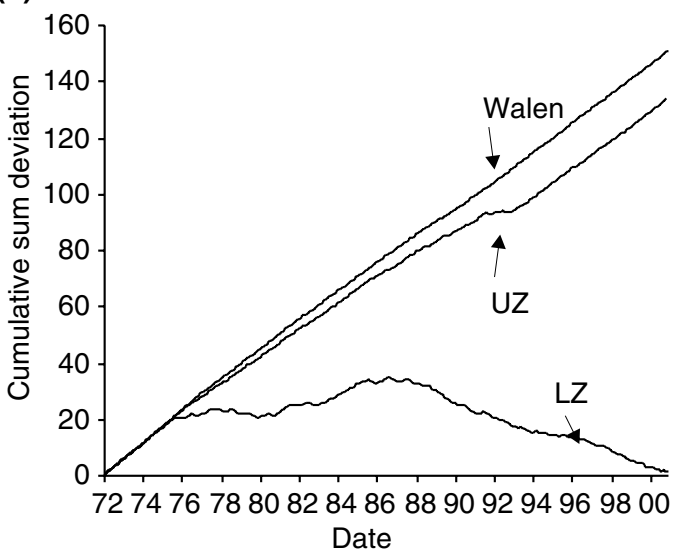

(b)

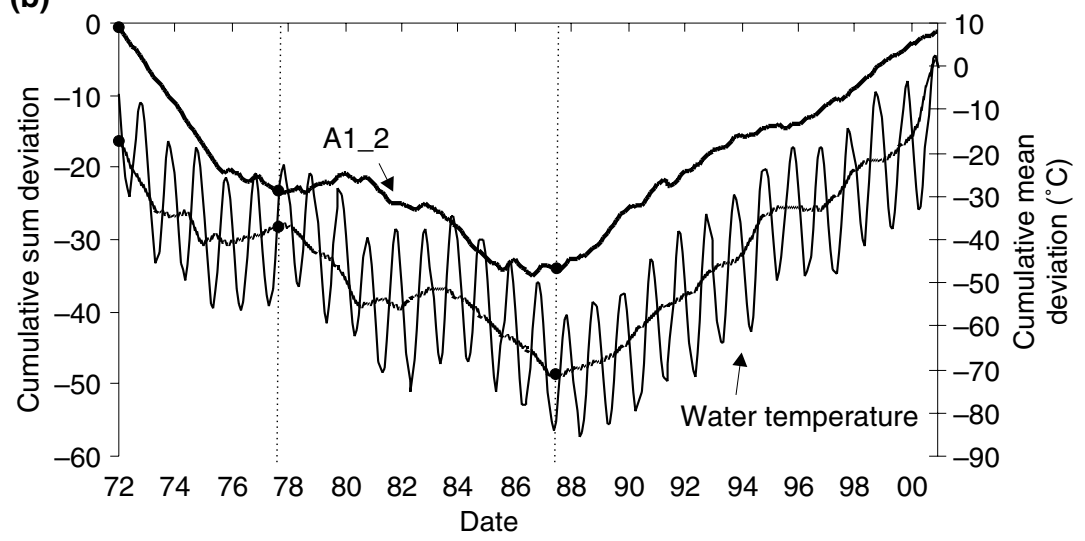

Fig. 6 (a) Cumulative sum series of A1_1 probabilities for the Walen, UZ and LZ Lakes. The three cumulative functions were obtained by subtracting 0.5 from data ranging between 0 and 1 , and then successively adding the residuals. Increasing slopes indicate the occurrence of A1_1 (for probabilities of more than 0.5) whereas decreasing slopes indicate low probabilities of occurrence. (b) Cumulative sum series of A1_2 probabilities for LZ compared with the cumulative deviation of the water temperature from the long-term mean for 1972-2000. This cumulated function is smoothed with a 12-point moving average.

(Fig. 6a). In contrast, in Lake LZ probabilities $>0.5$ occurred from 1972-76, and thereafter probabilities fluctuated strongly, and were high only during June. Finally probabilities have been $<0.5$ in LZ since 1987 (Fig. 6a). The year 1988 therefore marks the beginning of a divergence between the lakes and the beginning of a period in which LZ was dominated by assemblage A1_2. A1_2 displays a pattern of probability that is strongly related to the pattern observed in watertemperatures (Fig. 6b). Comparison of the cumulative sums of A1_2 probabilities and water temperature reveals similar trends between the two curves. A1_2 is associated with warmer water. A1_2 displays high probabilities in UZ where, from around 1979-92, it characterises the late summer and autumn months, but shows no relationship with temperature.

Structure 2: interlake and long-term variability. The second level of resolution also reveals both interlake and long-term variability. At this step, the cluster that was associated with A1_1 split into two new clusters, corresponding to assemblages A2_1 and A2_2 (Fig. 4). This level of partition reveals longterm changes marked by the relatively synchronous appearance of the A2_2 assemblage in the mid 1990s in Lakes Walen and UZ (Fig. 7). Pearson correlation coefficients between the monthly probability time series of these lakes are significant $(P<0.0001$ with $r$ ranging from 0.3 to 0.7 ) and indicate synchronous behaviour of occurrence. The main indicator of this assemblage is Kirchneriella, which is usually observed in clear water, and to lesser extent genera such as Gomphonema and Kephyrion and the mixotrophic Dinobryon accompanied by genera such as Mallomonas.

Structure 3: interlake and seasonal variability. Interlake and seasonal variability appear at the third level of resolution. The new assemblages A3_1 and A3_2 revealed by this stage occurred only in Lake UZ and LZ. The clusters result from the split of the cluster associated with the A1_2 assemblage (Fig. 4). A3_1 is 


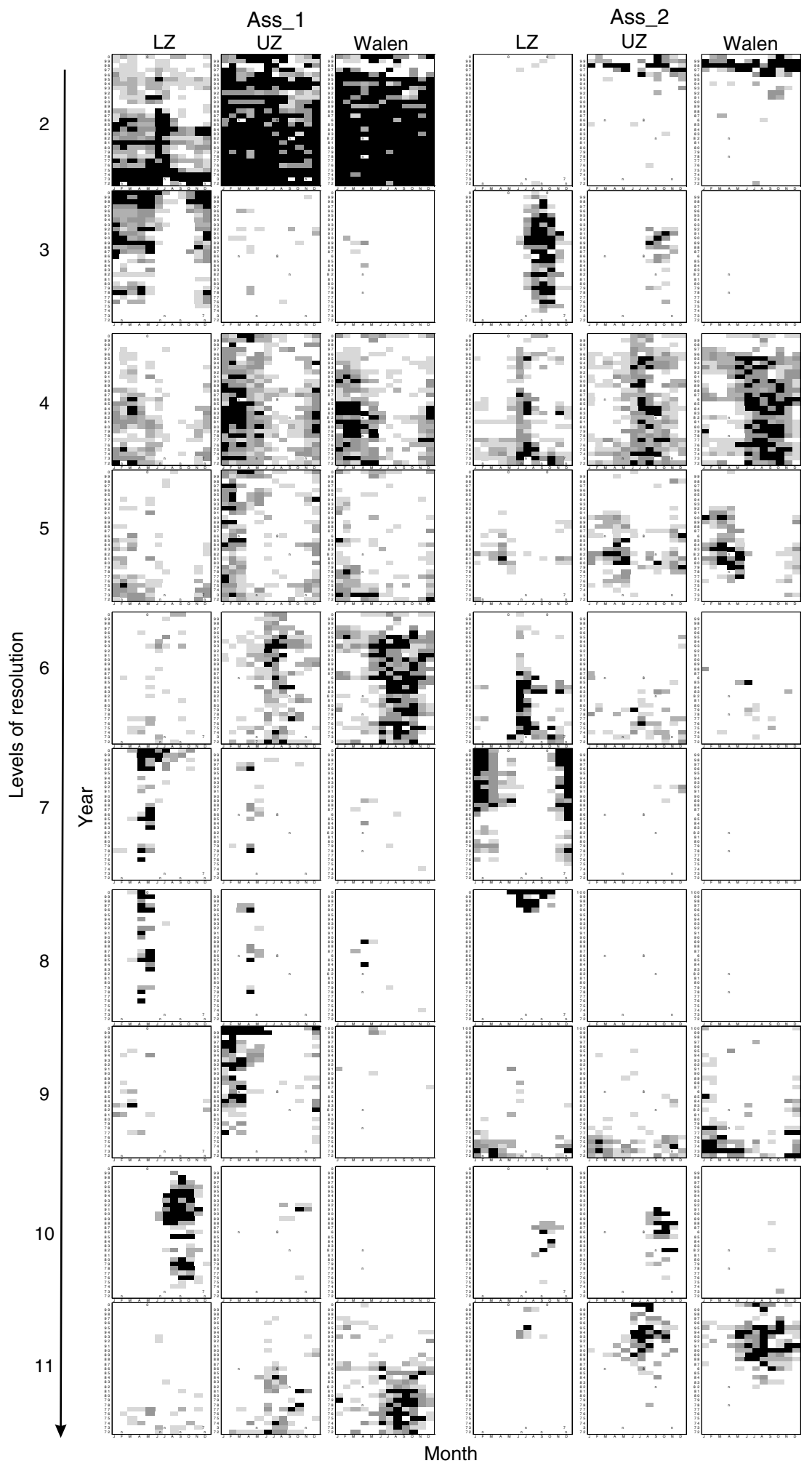

Fig. 7 Temporal maps of isoprobabilities describing the pattern of occurrence for the two assemblages (assemblage 1 and 2) obtained at each successive level of resolution. In each map, the time scale (years, from 1970 to 2000) runs from bottom to top and the season scale (months, from January to December) runs from left to right. The darker the pixels, the higher the probabilities. 


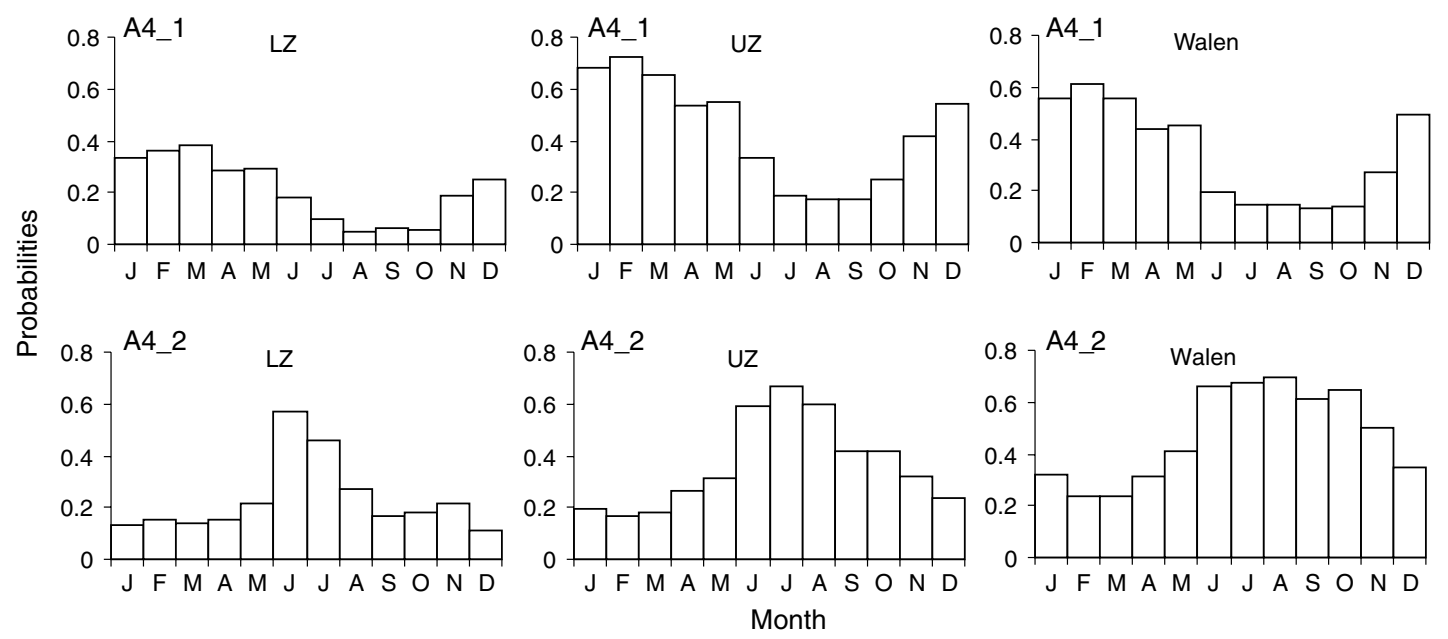

Fig. 8 Histograms of monthly average probabilities recorded for assemblages A4_1 and A4_2 in the Walen, UZ and LZ Lakes.

nearly absent in UZ (Fig. 7). It is associated with winter-spring and autumn months in LZ, and its probability has been on average higher since 1997. Furthermore, like assemblage A1_2, its pattern of occurrence exhibits strong synchronism with the trend observed in water temperature. Both probability and cumulative sums of A3_1 are significantly associated with water-temperatures (Pearson coefficient $r=-0.49, n=350, P<0.0001)$ and the cumulative sums of water temperatures (Spearman coefficient $r=0.69, \quad n=350, \quad P<0.0001)$. A3_2, which is characterised by genera such as Mougeotia, Phacotus and Pediastrum (Fig. 4), has the greatest probability of occurrence during the summer months from July to October in LZ and from August to November in UZ.

Structure 4: seasonal variability. The fourth level of resolution reveals seasonal variability (Fig. 8). The two clusters that appear at this stage were found in all the lakes. They result from the split of the cluster associated with assemblage A2_1 (Fig. 4). Assemblage A4_1 displays its highest probability of occurrence from January to May. A4_2 is present during the second half of the year, but its average pattern of occurrence differs from one lake to another. Its highest probability is mainly restricted to June and July in LZ, whereas this high probability extends until August in UZ and until November in Lake Walen. The probability values of assemblage A4_1 are on average lower in recent years, for they are mainly characterised by
A2_2 in the mid 1990s in Lake Walen and UZ, and by A3_1 and A3_2 in LZ (Fig. 7).

Structure 5: inter-annual variability in winter. The fifth level of resolution reveals winter-spring inter-annual variability (Fig. 7). A5_1 and A5_2 are present in all the lakes, and result from the split of the A4_1 assemblage described above (Fig. 4). A5_2 dominated mainly during the cold years (late 1970s to mid 1980s) and was maintained until the early 1990s in Lakes UZ and Walen (Fig. 9). The long-term changes in the winter-spring (November to May) mean probabilities for A5_2 reveal significant synchrony between lakes (all $P<0.0001$, all $r \geq 0.7, n=29$ ).

Structure 6: interlake variability in summer. The two next clusters result from the split of the cluster associated with assemblage A4_2 (Fig. 4). This level of resolution reveals interlake summer variability (Fig. 7). The new assemblage A6_1 extends over all years and all months in Walen and UZ. However, the higher probabilities are restricted to the stratified period, and can be maintained until November in Lake Walen. A6_2 is likely to occur principally in LZ (Fig. 7). Its high probabilities of occurrence are mainly restricted to June and July, but in some years they extend until autumn.

Structure 7: one lake seasonal and inter-annual variability. The seventh level of resolution focuses on the seasonal and interannual variability of Lake LZ. The 


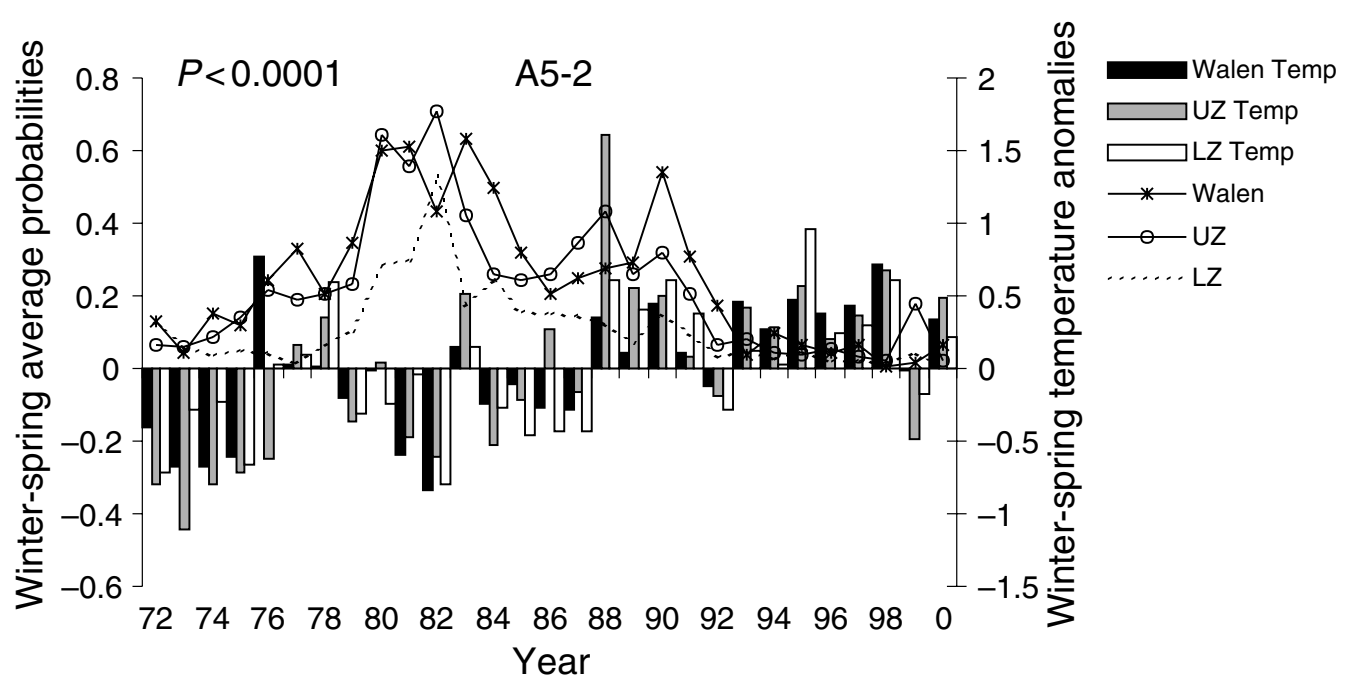

Fig. 9 Interlake comparison of long-term changes in winter-spring (from November to May) averages of A5_2 probabilities. The bars represent long-term changes in temperature anomalies, negative values indicate years in which the temperature was lower than the reference values (winter-spring means for 1972-2000). $P$ stands for the minimum $P$-value obtained for the correlation between the A5_2 probability values for the different lakes.

two new clusters associated with assemblages A7_1 and A7_2 result from the cluster associated with assemblage A3_1 (Fig. 4) and only occur in LZ. A7_1 presents high probabilities during spring (April to May) and in the summer months in the 1990s. It has been the most probable summer community since 1996 (Fig. 7). Assemblage A7_2 prevails from November to March during almost the entire period, but its probabilities of occurrence have been higher since the middle of the 1980s (Fig. 7).

Structure 8: one lake seasonal variability. At the eighth level of resolution, the seasonal pattern of phytoplankton assemblages becomes more detailed in LZ. The spring-summer cluster previously described now splits into two new clusters. One can be identified with a spring assemblage A8_1 consisting of Diatoma that was maintained from around 1983 to 2000 (Fig. 7). The other cluster is a summer assemblage A8_2 and characterises the end of the 1990s (Fig. 7). It is best characterised by Tabellaria and Ankyra, but also Fragilaria, Planktothrix, Kirchneriella, Pseudopedinella and Dinobryon (Fig. 4).

Structure 9: long-term variability. The ninth level of resolution reveals a long-term variability common to all three lakes. The winter cluster associated with assemblage A5_1 splits into two new clusters associated with A9_1, characteristic of the 1980s and 1990s in UZ and A9_2, characteristic of the 1970s in all three lakes (Fig. 7). Correlations between the average winter (November to May) probabilities of occurrence for A9_2 in the three lakes are highly significant $(P<0.0001, r \geq 0.78, n=29)$.

Structure 10: interlake variability in summer. The tenth level of resolution shows interlake variability in summer. The Lake Zurich summer cluster revealed at the third level splits into new clusters associated with assemblage A10_1, characteristic of LZ, or with assemblage A10_2, more characteristic of UZ (Fig. 7) and composed of the genera Cyclotella, Dinobryon often recorded in nutrient-poor habitats.

Structure 11: two-lake long-term variability in summer. The eleventh level of resolution reveals longterm summer variability in two lakes (Fig. 7). The new clusters are associated with assemblages A11_1 and A11_2, and they result from the split of the cluster associated with A6_1. These two new assemblages therefore have very low probabilities of occurring in LZ. Assemblage A11_1, characterised by Nitzschia, is more likely to be found during the cold years in the 1970s and 1980s in Lakes Walen and UZ (Fig. 7). Then, at the end of the 1980s, when winter-spring temperatures became warmer, in both lakes phytoplankton 

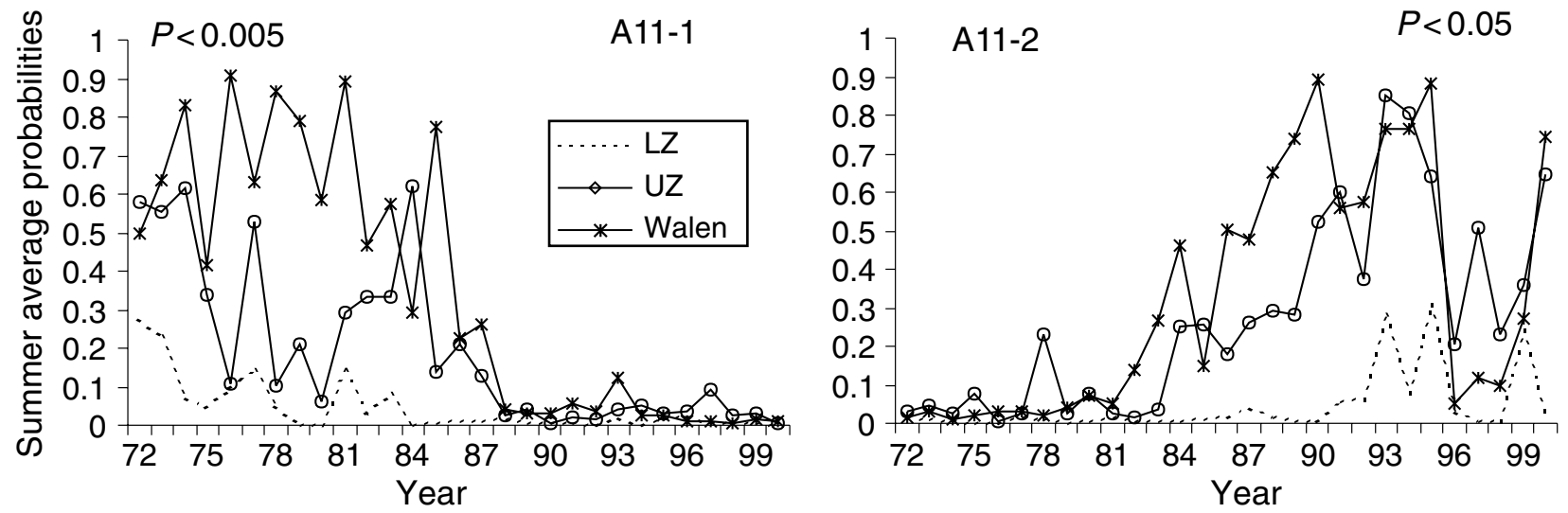

Fig. 10 Long-term changes in summer (July to September) averages of A11_1 and A11_2 probabilities. $P$ stands for the minimum $P$-value obtained for the correlation between the A11_1 and A11_2 probability values for the different lakes.

communities switched into assemblage A11_2, which has no indicator taxa (Fig. 7). Correlations between the summer means probability time-series are significant $(n=29, P<0.005$ with $r \geq 0.51$ for A11_1 and $P<0.05$ with $r \geq 0.45$ for A11_2), indicating temporal coherence between lakes for the occurrence of these assemblages (Fig. 10).

\section{Discussion}

The final phytoplankton composition is the consequence of a balance between gains and losses within the pool of those species, which have the adaptations required to survive in the environment (Reynolds, 1997). Sedimentation, grazing, light, $\mathrm{CO}_{2}$ or nutrients start to distinguish among the attributes of the phytoplankton species, and to select in favour of those better adapted to deal with the particular environment. The community is thus simultaneously structured by a tension among abiotic external forces (local conditions, such as nutrient concentration and temperature) and biotic internal forces (competition). The study reported here cannot provide any information about the relative strength of external and internal forces. However it does provide some clues about external forcing that induces the composition to change.

Factors causing the dominance of particular taxa are often difficult to identify because several interacting factors are usually involved, and these are not necessarily the same in different environments. In contrast, assuming that species likely to co-occur should share advantageous life traits, which make them more effective in the same environment, phytoplankton assemblages could be used to detect factors responsible for changes and synchronism between lakes.

As well as being able to identify phytoplankton assemblages, the method used in this study has two advantages: there is no need to choose a scale of observation and the occurrence of assemblages is assessed in terms of probability. Indeed, considering several temporal scales simultaneously reveals that each assemblage presents patterns of occurrence at the spatial, seasonal and inter-annual scales. Furthermore, temporal changes in ecosystems can often be described as a regular process (Frontier \& Pichod-Viale, 1991) with some sudden transitions depending on the severity of the disturbance (Petraitis \& Latham, 1999). As a consequence, communities blend gradually into another, so that communities overlap in a continuum and there are no sharply defined boundaries. In such a situation of continuum in change, partly because of the phenomenon of persistence of species or the memory of the system (Padisák, 1992), probabilities can be used to address the problem of overlapping assemblages. Finally, the combination of a hierarchical clustering with Bayesian probabilities makes it possible to detect synchronous patterns of occurrence of the phytoplankton assemblages in different lakes. Then, taking into account the hierarchy of the method, by analysing the assemblages obtained at different 'resolutions' (cut-off levels) reveals an ordination of factors responsible for (1) the phytoplankton community structure and (2) the synchrony between the lakes. 
Hierarchical ordination of the factors responsible for phytoplankton community structures

Differences in the make-up of the flora in the lakes are striking when analysing the structure of the phytoplankton communities. Although the lakes are geographically close and are subjected to similar climatic and anthropogenic forcing (Fig. 2), phytoplankton composition appears to be controlled primarily by local conditions. The first level of resolution segregates LZ from the two other lakes. The main reason for this differentiation between the lakes is the presence of Planktothrix represented by just one species:Planktothrix rubescens. Planktothrix rubescens is nearly absent in the meso-oligotrophic Lakes Walen and UZ, while it makes up $25 \%$ of the total biomass recorded in LZ over the study period. This species may be promoted by the hydrodynamic conditions in LZ, which has a warmer and shallower epilimnion and a very distinctive metalimnion compared with the other two lakes. P. rubescens may also benefit from the much higher phosphorus concentration that classifies LZ as being in a eutrophic and then mesotrophic state, whereas the other two lakes have remained in the meso-oligotrophic range. This species is promoted by the cultural eutrophication of many peri-alpine lakes, and it is recognised as the classic Central European indicator alga of eutrophication (Sommer, 1986). However, the relationship between trophic state and $P$. rubescens is still not clear, since $P$. rubescens tends to persist in European lakes despite marked decreases in phosphorus concentration (Feuillade, 1994; Morabito, Ruggiu \& Panzani, 2002). The ecological preferences of the other indicator taxa, which make up the two assemblages, confirm this segregation because of differences in the trophic conditions of the lakes. The greatest indicator values are assigned to genera recorded in habitats ranging from mesotrophic to hypertrophic (Synedra, Aphanizomenon, Microcystis) and characterise the association A1_2. In contrast, $\mathrm{Cyc} /$ Steph, an indicator of meso-oligotropic conditions, and Asterionella present their greatest value for A1_1. Asterionella can be present in eutrophic waters, but in association with Tabellaria, which also presents its greatest value for A1_1, and Cosmarium, it describes some oligo-mesotrophic lakes that support the Reynolds B-type association that is tolerant of light deficiency (Reynolds, 1998).
However, the segregation of LZ from the two other lakes becomes more obvious after 1987, despite the fact that $\mathrm{P}$ concentrations were tending to equal the concentrations observed in Lakes Walen and UZ. This suggests that in addition to differences in trophic state, other environmental factors are involved. Indeed, 1988 appears as the starting point for assemblage A1_2 in Lake LZ and this pattern is refined at the seventh level, when it concerns only the unstratified period. The occurrence of a community dominated by $P$. rubescens displays a strong correlation with long-term changes in water temperature, as does the biomass of this species. Planktothrix rubescens is already present at high biomass in summer for it is well adapted to environmental conditions characterised by very low phosphorus concentrations in the surface and levels that are still high in deeper layers (Anneville et al., 2002a). Because of its ability to cope with low light intensity, this species can go on developing until late autumn, when the average light received by the cell is reduced because of increasing mixing. During warm winters, it can persist all year round. In warm winters, or in winters with low wind activities, the mixing depth in LZ reaches only 60-100 m (Bossard, Gammeter \& Lehmann, 2001). During these years, winter mixing is therefore deep enough to prevent growth, but not deep enough to bring about the collapse of gas vesicles through exposure to excessive pressure. Consequently, when the mixing depth does not exceed the mean critical pressure depth (about $90 \mathrm{~m}$ ), most of the filaments remain buoyant at the end of the winter and can float up and form the inocula for growth during the next season (Walsby, Avery \& Schanz, 1998).

The next source of variability has induced longterm changes in Lakes Walen and UZ. During the second half of the 1990s, diatoms were no longer dominant and a new community was formed, which was composed of mixotrophic (Dinobryon) and clearlake (Kirchneriella) taxa. The observed changes comply with the classical picture of re-oligotrophication characterised by a shift in favour of mixotrophic species or species adapted to low nutrient concentrations (Gaedke, 1998; Kümmerlin, 1998; Anneville, Ginot \& Angeli, 2002b). These changes are therefore most likely a response of the phytoplankton community to the decrease in $\mathrm{P}$ concentrations. 
The lakes studied are located in a temperate area and despite different seasonal changes in the physical properties, zooplankton density, nutrient dynamics and turbidity (Zurich Water Supply, unpublished data), similar seasonal patterns appear at the third and fourth levels of precision. The description of this seasonality improves at higher levels of resolution in LZ. In contrast, the seasonal pattern displays considerable year-on-year irregularity beyond the fourth level of resolution in UZ and Walen. Such interannual irregularity could be due to the influence of stochastic meteorological and hydrological events, as is the case in small and shallow lakes that tend to have less regular phytoplankton development because of their major susceptibility to external disturbances (Sommer et al., 1986; Salmaso \& Decet, 1997).

\section{Temporal coherence in phytoplankton changes and factors of synchronism}

Most of the different phytoplankton assemblages described here display strong seasonal and/or interannual coherence in their pattern of occurrence among the lakes. Three factors could be causing communities to become synchronised in the lakes studied. The first factor is the long-term change in climatic conditions that is affecting water temperatures. It does not have the same degree of impact in all the lakes, because its effects appear at the first level in LZ but only at the eleventh level in UZ and Walen. In these latter two lakes, the main synchronising factor is the decline in the phosphorus concentration, the effect of which appears from the second level of determination. Finally, at a finer time scale, the seasonality in weather conditions, though influencing stratification, leads to a coherent pattern of annual phytoplankton successions in the lakes.

However, synchronous changes in composition do not necessarily imply the presence of the same phytoplankton assemblages. The temporal maps of assemblages show that synchronism can involve different genera (Fig. 7). Environmental factors first limit the composition to species able to inhabit a site (Reynolds, 1984; Weiher, Clarke \& Keddy, 1998). As a consequence, in neighbouring lakes influenced by similar large-scale factors, the ecological processes can have different outcomes because of local physicochemical and biological properties (Reynolds, Dokulil \& Padisák, 2000). For instance, the middle of the 1990s was marked by changes in summer phytoplankton communities. Summers became characterised by A8_2 in LZ, whereas A2_2 appears in UZ and Walen. The appearance of these assemblages is thought to have been induced by a decrease in nutrient concentration, because the new assemblages are characterised by taxa that are more or less characteristic of oligomesotrophic waters such as Kirchneriella, Pseudopedinella and Dinobryon. However, in LZ, A8_2 additionally includes some $\mathrm{R}$ strategists (Tabellaria, Fragilaria and Planktothrix, Fig. 4) able to tolerate low light intensities. The development of such taxa could be induced by a change in the vertical distribution of phosphorus and the presence of a metalimnic phosphorus-depleted layer while phosphorus concentrations remained high below the thermocline. Under such conditions species located at a deeper level, where light becomes a critical factor but where episodic incursions from deep, richer layers occur, might be able to gain some advantage from having the physiological ability to cope with low light intensity (Anneville et al., 2002a). Such synchronism including different assemblages is also well represented at the annual scale.

\section{Seasonal phytoplankton composition pattern}

In the three lakes, the winter and spring months are characterised by assemblages that are composed of genera displaying a shape that supports high metabolic rates, pre-adaptations that maximise their suspension opportunities, sensitivity to stratification or adaptation to low light intensities. These winterspring communities consist of a set of C (Stephanodiscus, Rhodomonas, Chlamydomonas) and R (Planktothrix, Diatoma, Asterionella, Fragilaria) strategists (Reynolds, 1997) that are tolerant of or dependent upon mixing. The clear-water phase usually observed in eu/mesotrophic habitats (Sommer et al., 1986) is observed every year in LZ and this is reflected in the phytoplankton, zooplankton counts and Secchi depth (Schanz, 1994), but it is not apparent in our results. The monthly sampling frequency was not high enough to detect the rapid changes involved in the clear-water phase. Instead, in LZ the winter assemblage is followed by an early summer assemblage, which is usually replaced by a late summer one (A3_2), consisting of both S and R strategists tolerant of mixing conditions. This late summer assemblage 
can periodically be found in UZ. At the end of the 1990s, the summer community was characterised by A8_2, which appears as early as June and mainly characterised by the $\mathrm{R}$ and $\mathrm{C}$ strategists Tabellaria and Ankyra. In Lakes Walen and UZ the seasonal pattern consists of less steps. Winter-spring assemblages are replaced by a set of large genera (A4_2) whose motility (Ceratium, Pandorina) provides an adaptation to the stratified summer conditions (Elliott, Reynolds \& Irish, 2000). This summer community contains more $\mathrm{R}$ strategists (Nitzschia, Asterionella, Fragilaria) tolerant to low light intensities and therefore adapted to autumnal conditions and to the typical summer turbidity caused by suspended particles from the rivers. Colony-forming diatoms able to grow very fast (Asterionella, Fragilaria) can suddenly occur in the middle of summer, usually after heavy rain periods when phosphorus enters the lake via many small streams.

The assemblages found in LZ differ from those observed in Lake Walen and UZ, being characterised by different combinations of genera in accordance with the degree of trophy, but at the annual scale their dynamics present the same pattern of the succession of life-strategists with assemblages dominated by $\mathrm{C}$ and $\mathrm{R}$ strategists (Stephanodiscus, Rhodomonas, Chlamydomonas, Planktothrix, Diatoma, Asterionella, Fragilaria) from January to May and then by S and R (Ceratium, Aphanizomenon, Oocystis, Microcystis, Tabellaria, Nitzschia, Asterionella, Fragilaria). After 1976, the seasonal pattern in LZ contained more steps than in the less-eutrophic lakes. This finding agrees with comparative studies of Sommer (1986), who found that the number of successive stages seems to increase with ascending eutrophy (from oligotrophy to eutrophy), probably because there are several situations in eutrophic lakes, such as the sudden change from nutrient-rich to nutrientpoor conditions, that do not occur in oligotrophic lakes.

In conclusion, this study based on the analysis of a large database obtained from monitoring programs of three connected lakes in Switzerland showed that the use of adequate taxonomic level (genera) for long-term phytoplankton datasets, coupled with multivariate statistical analyses, allowed coherences and differences between the dynamics of the three lakes to be distinguished. The synchrony between the lakes could easily be tested by the use of probability of occurrence of phytoplankton assemblages. The effect of long-term climatic changes on phytoplankton was distinguished from those due to local hydrological conditions and phosphorus appears as the main factor responsible for phytoplankton community structure. Decrease in phosphorus concentration leads to the appearance of new phytoplankton assemblages in all the lakes, while meteorological changes have a synchronising influence at both the annual and interannual scales. However, because of local differences, in particular in phosphorus concentrations, similar external largescale drivers could place constraints on different resources and cause interlake differences in the bestfitted traits of species, resulting in between lakes differences in the phytoplankton assemblages involved in synchronisms.

\section{Acknowledgments}

The authors are grateful to the Zurich Water Supply for providing the data and to Monika Ghosh for checking the English. Orlane Anneville was supported by a Marie Curie Individual Fellowship of the European Commission. This paper is a contribution to the IFB 'Institut Français de la Biodiversité' project 'Biodiversite et changement global' and to the European Commissions's Environment and Sustainable Development Programme under contract EVK1-CT2002-00121 (CLIME).

\section{References}

Anneville O., Souissi S., Ibanez F., Ginot V. \& Angeli N. (2002a) Temporal mapping of phytoplankton assemblages in Lake Geneva: annual and interannual changes in their patterns of succession. Limnology and Oceanography, 47, 1355-1366.

Anneville O., Ginot V. \& Angeli N. (2002b) Restoration of Lake Geneva: expected versus observed responses of phytoplankton to decreases in phosphorus. Lakes and Reservoirs: Research and Management, 7, 67-80.

Beaugrand G., Ibanez F. \& Reid P.C. (2000) Spatial, seasonal and long-term fluctuations of plankton in relation to hydroclimatic features in the English Channel, Celtic Sea and Bay of Biscay. Marine Ecology Progress Series, 200, 93-102.

Bossard P., Gammeter S. \& Lehmann C. (2001) Limnological description of the Lakes Zürich, Lucerne, and Cadagno. Aquatic Sciences, 63, 225-249. 
Breitburg D.L., Sanders J.G., Gilmour C.C., Hatfield C.A., Osman R.W., Riedel G. F., Seitzinger S.P. \& Sellner K.G. (1999) Variability in responses to nutrients and trace elements, and transmission of stressor effects through an estuarine food web. Limnology and Oceanography, 44, 837-863.

Dufrêne M. \& Legendre P. (1997) Species assemblages and indicator species: the need for a flexible asymmetrical approach. Ecological Monographs, 67, 345-366.

Elliott J.A., Reynolds C.S. \& Irish T.E. (2000) The diversity and succession of phytoplankton communities in disturbance-free environments, using the model PROTECH. Archiv für Hydrobiologie, 149, 241-258.

Feuillade J. (1994) Studies on Lake Nantua: Foreword by the guest editor. Archiv für Hydrobiologie, Beiheft Ergebnisse der Limnologie, 41, 5-9.

Folt C.L., Chen C.Y., Moore M.V. \& Burnaford J. (1999) Synergism and antagonism among multiple stressors. Limnology and Oceanography, 44, 864-877.

Frontier S. \& Pichod-Viale D. (1991) Ecosystèmes: structure, fonctionnement, évolution. Collection d'écologie 21, Masson, Paris, 392p.

Gaedke U. (1998) Functional and taxonomical properties of the phytoplankton community of large and deep Lake Constance: interannual variability and response to re-oligotrophication (1979-1993). Archiv für Hydrobiologie, Special Issues Advanced Limnology, 53, 119-141.

Harrington R., Woiwod I. \& Sparks T. (1999) Climate change and trophic interactions. Tree, 14, 146-150.

Hurrell J.W. (1995) Decadal trends in the North Atlantic Oscillation: regional temperatures and precipitations. Science, 269, 676-679.

Ibanez F., Fromentin J.M. \& Castel J. (1993) Application de la méthode des sommes cumulées à l'analyse des séries chronologiques en océanographie. Life Sciences, 316, 745-748.

Koenig W.D. (1999) Spatial autocorrelation of ecological phenomena. Tree, 14, 22-26.

Kümmerlin R.E. (1998) Taxonomical response of the phytoplankton community of Upper Lake Constance (Bodensee-Obersee) to eutrophication and re-oligotrophication. Archiv für Hydrobiologie, Special Issues Advanced Limnology, 53, 109-117.

Levin S.A. (1992) The problem of pattern and scale in ecology. Ecology, 73, 1943-1967.

Lindenschmidt K.E. \& Chorus I. (1998) The effect of water column mixing on phytoplankton succession, diversity and similarity. Journal of Plankton Research, 20, 1927-1951.

Magnuson J.J. \& Kratz T.K. (2000) Lakes in the landscape: approaches to regional limnology. Verhandlungen der Internationalen Vereinigung für Limnologie, 27, 74-87.
Magnuson J.J., Benson B.J. \& Kratz T.K. (1990) Temporal coherence in the limnology of a suite of lakes in Wisconsin, USA. Freshwater Biology, 23, 145-159.

Morabito G., Ruggiu D. \& Panzani P. (2002) Recent dynamics (1995-1999) of the phytoplankton assemblages in Lago Maggiore as a basic tool for defining association patterns in the Italian deep lakes. Journal of Limnology, 61, 129-145.

Padisák J. (1992) Seasonal succession of phytoplankton in a large shallow lake (Balaton, Hungary), a dynamic approach to ecological memory, its possible role and mechanisms. Journal of Ecology, 80, 217-230.

Paerl H.W. (1988) Nuisance phytoplankton blooms in coastal, estuarine, and inland waters. Limnology and Oceanography 33, 823-847.

Petraitis P.S. \& Latham R.E. (1999) The importance of scale in testing the origins of alternative community states. Ecology, 80, 429-442.

Reynolds C.S. (1984) The Ecology of Freshwater Phytoplankton. Cambridge University Press, Cambridge, 384 pp.

Reynolds C.S. (1996) The plant life of the pelagic. Verhandlungen der Internationalen Vereinigung für Limnologie, 26, 97-113.

Reynolds C.S. (1997) Vegetation Processes in the Pelagic: A Model for Ecosystem Theory. Ecology Institute, Germany, 371 pp.

Reynolds C.S. (1998) What factors influence the species composition of phytoplankton in lakes of different trophic status? Hydrobiologia, 11-26.

Reynolds C.S., Dokulil M. \& Padisák J. (2000) Understanding the assembly of phytoplankton in relation to the trophic spectrum: where are we now? Hydrobiologia, 424, 147-152.

Reynolds C.S., Huszar V., Kruk C., Naselli-Flores L. \& Melo S. (2002) Towards a functional classification of the freshwater phytoplankton. Journal of Plankton Research, 24, 417-428.

Salmaso N. \& Decet F. (1997) Seasonal and interannual changes of chemical characteristics and phytoplankton in a mountain lake of the eastern Italian Alps (Lake Calaita, Trentino). Internationale Revue der gesamten Hydrobiologie, 82, 15-31.

Sas H. (1989) Lake Restoration by Reduction of Nutrient Loading: Expectations, Experiences, Extrapolations. Academia Verlag, Richarz, 497pp.

Schanz F. (1994) Oligotrophication of Lake Zürich as reflected in Secchi depth measurements. Annales de Limnologie, 30, 57-65.

Seip K.L. \& Reynolds C.S. (1995) Phytoplankton functional attributes along trophic gradient and season. Limnology and Oceanography, 40, 589-597. 
Sommer U. (1986) The periodicity of phytoplankton in Lake Constance (Bodensee) in comparison to other deep lakes of central Europe. Hydrobiologia, 138, 1-7.

Sommer U., Gliwicz Z.M., Lampert W. \& Duncan A. (1986) The PEG-model of seasonal succession of planktonic events in fresh waters. Archiv für Hydrobiologie, 106, 433-471.

Souissi S., Ibanez F., Ben Hamadou R., Boucher J., Cathelineau A.C., Blanchard F. \& Poulard J.-C. (2001) A new multivariate mapping method for studying species assemblages and their habitats: example using bottom trawl surveys in the Bay of Biscay (France). Sarsia, 86, 527-542.

Straile D. (2002) North Atlantic Oscillation synchronizes food-web interactions in central European lakes. Proceedings of the Royal Society of London B, 269, 391-395.

Straile D., Livingstone D.M., Weyhenmeyer G.A. \& George D.G. (2003) The response of freshwater ecosys- tems to climate variability associated with the North Atlantic Oscillation. In: Geographical Monograph, 134, The North Atlantic Oscillation: Climatic Significance and Environmental Impact (Ed. J.W. Hurrel et al.), pp. 263279. American Geophysical Union, Washington, DC.

Utermöhl H. (1958) Zur Vervollkommnung der quantitativen Phytoplankton-Methodik. Mitteilungen der Internationalen Vereinigung für Limnologie, 9, 1-38.

Walsby A., Avery A. \& Schanz F. (1998) The critical pressures of gas vesicles in Planktothrix rubescens in relation to the depth of winter mixing in Lake Zurich, Switzerland. Journal of Plankton Research, 20, 13571375.

Weiher E., Clarke G.D.P. \& Keddy P.A. (1998) Community assembly rules, morphological dispersion, and the coexistence of plant species. Oikos, 81, 309-322. 